\title{
Processo de reciclagem química de PET em meio alcalino: efeito da concentração do íon hidróxido, da cor do PET e do tempo de reação
}

\section{Process of chemistry recycling of PET in \\ alkaline medium: effect of concentration \\ of hydroxide ion, color of PET \\ and reaction time}

Carmen Myrella Aparecida dos Santos ${ }^{1}$, Ana Cristina Resende Gonçalves ${ }^{1}$, Alessandra Cristina Cintra ${ }^{1}$, Luís Antônio da Silva ${ }^{1}$, Alexandre Rossi ${ }^{1}$, Herenilton Paulino Oliveira ${ }^{2}$, Valéria Almeida Alves ${ }^{1}$

\footnotetext{
${ }^{1}$ Departamento de Química, Instituto de Ciências Exatas, Naturais e Educação (ICENE), Universidade Federal do Triângulo Mineiro (UFTM), Uberaba, Minas Gerais, Brasil.

${ }^{2}$ Departamento de Química, Faculdade de Filosofia, Ciências e Letras de Ribeirão Preto (FFCLRP), Universidade de São Paulo (USP), Ribeirão Preto, São Paulo, Brasil.

e-mail: valeria.alves@uftm.edu.br, carmenmyrella@hotmail.com, anacris_rg@yahoo.com.br, alessandra-cintra@bol.com.br, luis.silva@uftm.edu.br, alexcrossiquim@gmail.comherepo@ffclrp.usp.br
}

\begin{abstract}
RESUMO
Este trabalho investigou o processo de hidrólise química de poli(tereftalato de etileno) (PET) em meio alcalino; especificamente de garrafas incolores e coloridas pós-uso. A reciclagem química de embalagens PET pós-uso ainda é muito pouco explorada no Brasil, não sendo tão diferente do que está sendo praticado em outros países. Dentre variáveis possíveis de investigação, aquelas estudadas neste trabalho foram a concentração de hidróxido de sódio $(\mathrm{NaOH})$ e a cor do PET. A reação de despolimerização do PET pós-uso foi realizada na concentração de 1,0, 3,0, 5,0, 7,5 e 10,0 mol L-1 de $\mathrm{NaOH}$, sendo que em 7,5 mol L $\mathrm{L}^{-1}$ foi aquela que mostrou os melhores resultados, relativamente à extensão da reação e à pureza do monômero recuperado, o ácido tereftálico (TPA). A reação também foi feita para PET de cores diferentes, na concentração de $7,5 \mathrm{~mol} \mathrm{~L}^{-1}$ de $\mathrm{NaOH}$, cujos resultados mostraram um menor desempenho quando comparados com aqueles obtidos para o PET não colorido. Esse resultado sugere ser devido à presença de corantes, que pela estrutura química dos mesmos, competem pelo ataque nucleofílico do íon hidroxila $\left(\mathrm{OH}^{-}\right)$, durante a reação de hidrólise do PET. As análises por Espectrofotometria no Infravermelho (FTIR), Difração de Raios X $(D R X)$ e Termogravimétrica $(T G A / D T G)$ confirmaram que os produtos de reação resultaram em TPA, uma vez que os espectros foram coincidentes com aqueles do TPA comercial. O crescente consumo de embalagens PET e o descarte ambiental aleatório precisam de soluções rápidas; os resultados do presente trabalho são importantes e corroboram com o avanço da pesquisa para a reutilização de matéria prima.
\end{abstract}

Palavras-chave: PET, hidrólise, reciclagem química.

\begin{abstract}
This work investigated the chemical hydrolysis process of polyethylene terephthalate (PET) in alkaline medium; specifically, colorless and colored post-consume bottles. The chemical recycling of post-consume PET bottles is still very little explored in Brazil, not being so different from what is being practiced in other countries. Among possible variables of investigation, in this work was studied the sodium hydroxide $(\mathrm{NaOH})$ concentration and the PET color. The post-consume PET depolymerization reaction was performed at the concentrations of 1.0, 3.0, 5.0, 7.5 and $10.0 \mathrm{~mol} \mathrm{~L}^{-1} \mathrm{NaOH}$, and in $7.5 \mathrm{~mol} \mathrm{~L}^{-1}$ was the one that showed the best results, regarding the extent of the reaction and the purity of the recovered monomer, terephthalic acid (TPA). The reaction was also made for PET of different colors at the concentration of $7.5 \mathrm{~mol} \mathrm{~L}^{-1} \mathrm{NaOH}$,
\end{abstract}


whose results showed a lower performance when compared to those obtained for non-colored PET. This result suggests that it is due to the presence of dyes, which, due to their same chemical structure, compete for nucleophilic attack of the hydroxyl ion $\left(\mathrm{OH}^{-}\right)$during the hydrolysis reactionof of PET. Infrared Spectrophotometry $(F T I R)$, X-ray diffraction $(X R D)$, as well as Thermogravimetric (TGA / DTG) analysis confirmed that the reaction products resulted in TPA, since the spectra were coincident with those of the commercial TPA. The increasing consumption of PET packaging and aleatory environmental disposal need quick solutions; the results of this work are important and corroborate with the advance of the research for reutilization of raw material.

Keywords: PET, hydrolysis, chemistry recycling.

\section{INTRODUÇÃO}

A introdução de embalagens de poli(tereftalato de etileno) (PET) no Brasil ocorreu na década de 80, trazendo vantagens indiscutíveis, mas trouxe também um grande desafio no que diz respeito à sua reciclagem [1]. Face à atual preocupação com o meio ambiente e à necessidade urgente de sua preservação, faz-se necessário estabelecer estratégias para reduzir o acúmulo de PET na natureza, uma vez que o mesmo apresenta elevada resistência à degradação natural e baixa densidade, que contribuem para o aumento do volume de resíduos descartados no meio ambiente, lixões a céu aberto, rios, lagos e mares.

O PET, desenvolvido pelos químicos ingleses Whinfield e Dickson, em 1941 [1,2], é caracterizado por ser um copolímero de poliéster [2], preparado pela reação de condensação entre o etilenoglicol e o ácido tereftálico (TPA), como mostrado na Figura 1.

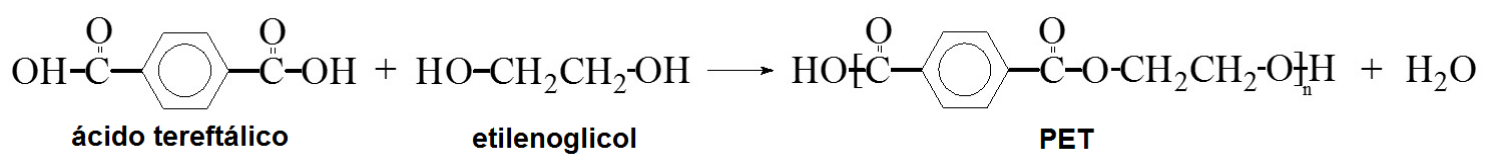

Figura 1: Reação de esterificação e estrutura molecular do poli(tereftalato de etileno) (PET). Adaptado da referência [3].

O Brasil consumiu aproximadamente 537.250 toneladas de resina PET na fabricação de embalagens em 2015 [4]. O maior consumo de PET reciclado é na fabricação de fibras para roupas e tapetes, na sequência de quantidade de consumo, o PET reciclado é usado na produção de garrafas para alimentos e bebidas e, por último, na fabricação de cordas, faixas, tiras, correias, alças e em recipientes para produtos não alimentares, como por exemplo, embalagens para xampu. Nos EUA, na Europa e na Austrália, os consumidores podem comprar refrigerantes envasados em garrafas PET produzidas com percentuais variados de material reciclado. No Brasil, as embalagens do Guaraná Antarctica ${ }^{\circledR}$ são totalmente fabricadas com PET reciclado desde 2012. Após autorização especial das agências reguladoras de cada país, é possível fabricar embalagens PET utilizando até $100 \%$ de material reciclado [5-10]. O avanço da pesquisa sobre processos de reciclagem química, processo no qual o PET pós-consumo é despolimerizado, irá favorecer a recuperação das matérias-primas básicas, com pureza e qualidade, para retornarem para as embalagens com $100 \%$ de PET reciclado.

Essa aplicação poderá crescer com essas matérias-primas recuperadas (etilenoglicol e ácido tereftálico) e devidamente purificadas, sendo possível produzir a resina PET novamente. A tecnologia mais conhecida é a bottle-to-bottle. No processo de reciclagem bottle-to-bottle as garrafas pós-consumo são selecionadas, moídas e limpas por um processo de intensa lavagem, que permite retirar todos os resíduos contaminantes. Após derretido, o PET reciclado é misturado ao PET virgem. O material resultante é injetado para a fabricação das pré-formas pelo processo convencional $[1,11,12]$.

Os números mostram que a cada ano, no Brasil, a aplicação do processo de reciclagem de embalagens de PET tem aumentado, mas ainda há muito por fazer para melhorar estes índices. Em 2015, a taxa de reciclagem no Brasil foi de $51 \%$, correspondendo a 574.000 toneladas. A redução da quantidade de PET reciclado no Brasil nos últimos anos está relacionada com a retração da indústria brasileira. Setores importantes, como têxtil, químico, automotivo e de transporte tiveram quedas de quase $50 \%$ em suas atividades, refletindo negativamente sobre a reciclagem, já que são grandes consumidores de matéria-prima reciclada [4].

Segundo ROSMANINHO et al. [3] a reciclagem química do PET tem atraído a atenção dos químicos devido à grande variedade de processos, resultando em diferentes produtos. Por exemplo, o PET pode ser 
reciclado por hidrólise catalítica [13], aminólise [14], alcoólise [15], glicólise [16] e mesmo para a produção de copolímeros por meio da reação com outros polímeros [17]. Uma comparação destas diferentes rotas, produtos obtidos e suas aplicações na indústria química é apresentada em uma revisão de autoria de NIKLES e FARAHAT [18].

O processo de reciclagem química do PET via hidrólise catalítica, utilizada também para outros plásticos, promove a despolimerização do PET, separando-o nos monômeros originais (etilenoglicol e ácidotereftálico, reação inversa da Figura 1). O processo de reciclagem química ainda é pouco aplicado no Brasil, o que não é muito diferente em outros países [19]. De acordo com MANCINI e ZANIN [20], a utilização da hidrólise catalítica como uma maneira de despolimerizar o poliéster está normalmente associada a sistemaspressurizados que permitam temperaturas superiores às da ebulição da água. Já sistemas desenvolvidos àtemperaturas e pressões baixas, normalmente empregam concentrações relativamente elevadas de reagentes que alterem o pH do meio, fornecendo íons à reação [21]. No caso da hidrólise em meio ácido, assim como em meio neutro, a reação de despolimerização é favorecida pela protonação do átomo de oxigênio da carbonila do éster, aumentando assim o caráter eletrofílico do átomo carbono carbonílico por moléculas de água presentes no meio. Assim, o ataque nucleofílico de moléculas de água ao carbono eletrofílico conduz à reação de hidrólise ácida. Em meio alcalino, a ausência de íons hidrogênio $\left(\mathrm{H}^{+}\right)$ para a reação de despolimerização é compensada pela presença do íon hidróxido $\left(\mathrm{OH}^{-}\right)$, o qual favorece a reação de hidrólise básica pelo seu maior caráter nucleofílico, quando comparado com o da água. O ácido conjugado da base, sendo mais forte que os poucos íons hidrogênio gerados pela ionização da água, completa a reação com a formação do sal do ácido tereftálico [21-24].

O processo de reciclagem química do PET é encontrado em alguns poucos trabalhos acadêmicos, sem mesmo ter havido a transferência da tecnologia para aplicação industrial [3,25-33]. A reciclagem química do PET ainda enfrenta diversos desafios; processos de reciclagem em larga escala são raramente encontrados. Isto se justifica pelo fato da reação de despolimerização do PET ser normalmente lenta, e por esse motivo deixam de ser interessantes do ponto de vista industrial. A reciclagem química apresenta vantagens em relação à descontaminação do PET com substâncias tóxicas e tem importância como processo alternativo à reciclagem mecânica. A principal desvantagem está relacionada com o fato do processo ser oneroso, devido à grande quantidade de energia consumida, além de contribuir com a emissão de gases de efeito estufa [34-37]. Pelo fato do processo da reciclagem química não ter sido completamente desenvolvido ao ponto de tornar-se economicamente viável para aplicação no setor industrial e por permitir a produção de novas embalagens para acondicionar bebidas e alimentos a partir da matéria-prima original e livre de impurezas, é que se justifica a necessidade de maiores investigações no sentido de aprimoramento da reciclagem química do PET.

Esse trabalho teve como objetivo investigar, sistematicamente, o processo de reciclagem química do PET em meio alcalino, no sentido de torná-lo mais rápido, economicamente viável e com possibilidade de aplicação no setor industrial, podendo até mesmo contribuir para que o Brasil venha a ocupar uma posição de destaque pela aplicação industrial do processo de reciclagem química. Neste trabalho alguns parâmetros não estudados antes por outros grupos de pesquisa trouxeram melhorias nos resultados em relação à possível aplicação prática da reação de despolimerização de embalagens PET pós-uso. Dentre esses parâmetros, podemos citar que o aumento do tempo de reação de 6 horas para 8 horas, bem como a diminuição da área superficial do PET, de $30 \mathrm{~mm}^{2}$ para $25 \mathrm{~mm}^{2}$, trouxeram uma contribuição para um maior rendimento da reação de despolimerização do PET. Ainda, utilizou-se a técnica de titulação ácido-base potenciométrica para a determinação da pureza dos produtos de reações de despolimerização do PET, a qual é considerada mais

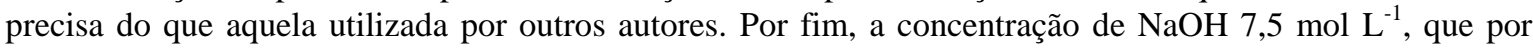
sinal levou a melhores resultados para a despolimerização do PET, também não havia sido explorada.

\section{MATERIAIS E MÉTODOS}

Embalagens de PET pós-uso, coletadas em lixo doméstico, foram separadas de acordo com a sua cor, cortadas em pedaços de $5 \mathrm{~mm}$ x $5 \mathrm{~mm}$ e posteriormente lavadas. A lavagem foi realizada usando banho de ultrassom da Unique, modelo USC-1400, modo normal de funcionamento, com frequência fixa na faixa de 40 a $60 \mathrm{kHz}$, em todas as etapas, durante10 minutos, as quais são mostradas na Figura 2. Após a lavagem, o PET foi secado em estufa, a $60{ }^{\circ} \mathrm{C}$, durante 5 horas. 


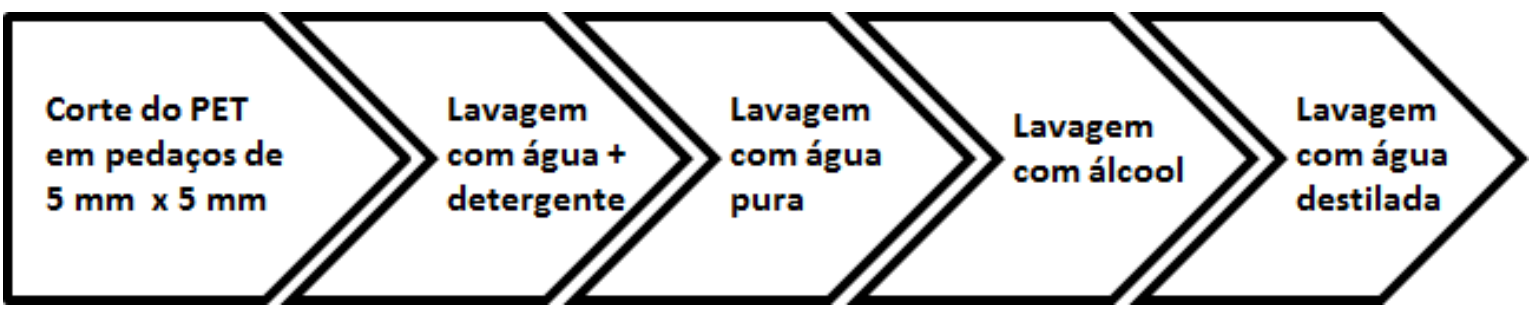

Figura 2: Sequência de etapas de lavagem do PET pós-uso.

Após a secagem do PET, as reações de hidrólise foram realizadas em duplicata e sob refluxo, em meio alcalino, $\mathrm{NaOH}$. O sistema de refluxo garantiu a temperatura constante em $100{ }^{\circ} \mathrm{C}$, durante o tempo de $8 \mathrm{~h}$, estipulado para as reações de hidrólise. O refluxo foi feito em balão de fundo redondo de $125 \mathrm{~mL}$, acoplado a uma manta de aquecimento apropriada e conectado a um condensador de bolas (Allhin). A temperatura e o tempo de reação são muito importantes para a reprodutibilidade dos resultados [3,29]. Utilizou-se $1,0 \mathrm{~g}$ de PET para cada $5,00 \mathrm{~mL}$ de solução aquosa de base de diferentes concentrações [31]. As concentrações da base utilizadas foram 1,$0 ; 3,0 ; 5,0 ; 7,5$ e $10 \mathrm{~mol} \mathrm{~L}^{-1}$. As reações de hidrólise alcalina também foram realizadas para PET colorido (amarelo, azul, verde e vermelho), durante $8 \mathrm{~h}$, mantendo a concentração da base

em 7,5 mol L ${ }^{-1}$. Outra variável foi o tempo de reação, que foi de $1 ; 2 ; 4$ e $6 \mathrm{~h}$, mantendo a concentração da base em 7,5 mol L ${ }^{-1}$. Nestes dois últimos estudos, fixou-se a concentração em 7,5 $\mathrm{mol} \mathrm{L}^{-1}$ em vista dos melhores resultados, no que tange o rendimento da reação e a pureza do TPA, recuperados com o PET incolor na presença de várias concentrações de base (vide Resultados e Discussão).

Para a obtenção do ácido tereftálico após as reações de hidrólise alcalina, a seguinte metodologia foi utilizada, a qual pode ser vista de forma esquemática na Figura 3:

1- Filtrou-se o resíduo que porventura permaneceu no meio reacional e lavou-o com água destilada.

2- Acidificou-se o filtrado com solução de ácido sulfúrico 1:5 $\left(\mathrm{H}_{2} \mathrm{SO}_{4} / \mathrm{H}_{2} \mathrm{O}\right.$, v/v), a fim de precipitar todo o ácido tereftálico produzido.

3- Filtrou-se o ácido tereftálico, lavou-se com solução de ácido sulfúrico 1:5 $\left(\mathrm{H}_{2} \mathrm{SO}_{4} / \mathrm{H}_{2} \mathrm{O}\right.$, v/v) e depois com água destilada, a fim de remover o excesso de ácido.

5- Secou-se em estufa a $75^{\circ} \mathrm{C}$ por $4 \mathrm{~h}$.

6- A massa do resíduo de PET, já seco em estufa a $75{ }^{\circ} \mathrm{C}$, também foi medida, a fím de se fazer os cálculos de rendimento de hidrólise [3,29].

O rendimento da hidrólise foi calculado baseando-se no consumo do PET na reação, de acordo com a Eq. (1):

$$
\operatorname{Re} n \operatorname{dim} \text { ento }=\frac{\left(m_{i}-m_{f}\right)}{m_{i}} \times 100
$$

onde: $\mathrm{m}_{\mathrm{i}}=$ massa do PET antes da reação e $\mathrm{m}_{\mathrm{f}}=$ massa do PET após a reação.

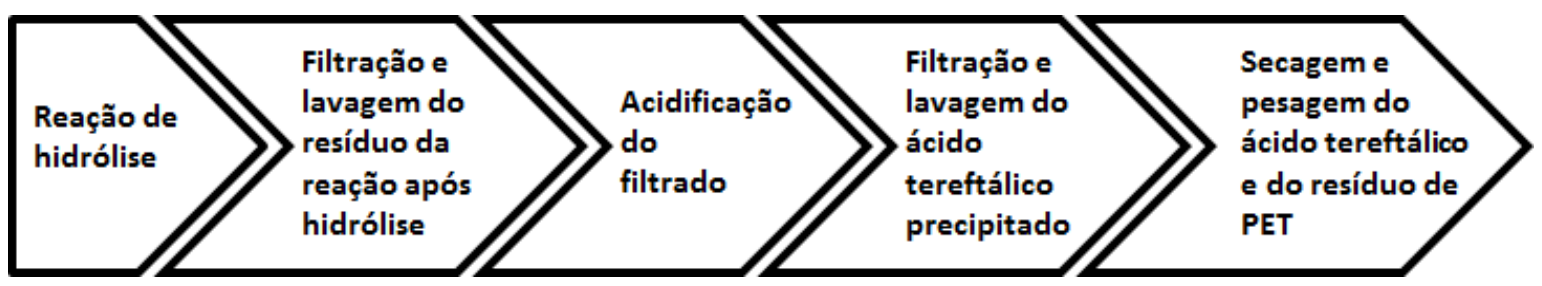

Figura 3: Sequência de etapas para obtenção/purificação do ácido tereftálico após hidrólise alcalina.

A partir das titulações potenciométricas ácido-base determinou-se o teor de pureza de amostras dos produtos das reações de hidrólise (que acreditava-se, até então, tratar-se de ácido tereftálico). Amostras dos 
produtos da reação, de aproximadamente $0,25 \mathrm{~g}$, foram medidas com precisão em balança analítica, solubilizadas em um volume definido e em excesso de solução padrão de $\mathrm{NaOH}(V=35,00 \mathrm{~mL}$; $\left.C=0,1 \mathrm{~mol} \mathrm{~L}^{-1}\right)$, já que o TPA apresenta baixa solubilidade em água $\left(19 \mathrm{mg} \mathrm{L}^{-1}\right.$, a $\left.25^{\circ} \mathrm{C}\right)$ [29]. Nesse caso, obtém-se o tereftalato de dissódio, que é solúvel. Para a completa solubilização do TPA foi necessária a utilização de um banho de ultrassom durante 10 min. $O$ titulante consistiu de uma solução padrão de ácido clorídrico, $C=0,1 \mathrm{~mol} \mathrm{~L}^{-1}$. Utilizou-se uma bureta digital de $50 \mathrm{~mL}$ de capacidade, precisão Classe A, marca Titrette, para realização das titulações, as quais foram realizadas em triplicata. O aparato para realizar a titulação potenciométrica ainda incluiu um pH-metro (Ávila Científica) e um mini agitador magnético, sem aquecimento (Tecnal, TE-080).

$\mathrm{Na}$ titulação, o número de mols de $\mathrm{NaOH}$ em excesso (que não reagiu com o ácido tereftálico da amostra) foi determinado. Consequentente, o número de mols de ácido tereftálico foi obtido pela diferença entre o número total de mols de $\mathrm{NaOH}$ adicionado e o número de mols que reagiu com o $\mathrm{HCl}$, dividido por dois, já que um mol de TPA reage com dois mols de $\mathrm{NaOH}$, conforme a estequiometria da Eq. (2).

$$
\mathrm{HOOCC}_{6} \mathrm{H}_{4} \mathrm{COOH}_{(\mathrm{s})}+2 \mathrm{NaOH}_{(\mathrm{aq})} \rightarrow \mathrm{OOCC}_{6} \mathrm{H}_{4} \mathrm{COO}_{(\mathrm{aq})}^{-}+2 \mathrm{Na}_{(\mathrm{aq})}^{+}+\mathrm{H}_{2} \mathrm{O}_{(\mathrm{l})}
$$

Para confirmar se as reações de hidrólise alcalina do PET realmente produziram o ácido tereftálico, amostras representativas do produto foram analisadas por Espectrofotometria no Infravermelho (FTIR), Difração de Raios X $(D R X)$, e por Termogravimetria $(T G A / D T G)$. Os espectros FTIR das amostras na forma de pastilhas de $\mathrm{KBr}, 2 \%(\mathrm{~m} / \mathrm{m})$, foram obtidos no intervalo de $4000 \mathrm{~cm}^{-1}$ a $400 \mathrm{~cm}^{-1}$ usando um espectrofotômetro da Bomem, modelo MB 100, com acessório de Reflectância Total Atenuada (ATR). A caracterização das amostras por $D R X$ foram realizadas com um difratômetro da Rigaku, usando radiação CuK $\alpha$ de $\lambda=1,5406 \AA$. Para as análises termogravimétricas pesou-se 9,7391 mg do TPA recuperado, análise representativa, e $0,9806 \mathrm{mg}$ do TPA comercial. As condições de análise foram as seguintes: suporte de amostra de $\alpha$-alumina aberto, razão de aquecimento de $10^{\circ} \mathrm{C} \mathrm{min}^{-1}$, iniciando na temperatura ambiente, sob vazão de ar sintético de $100 \mathrm{~mL} \mathrm{~min}^{-1}$. As curvas TGA/DTG das amostras foram obtidas com um analisador termogravimétrico da TA Instruments, modelo 2960 SDT V3.0F. Para fins de comparação, realizou-se também a mesmas medidas com o padrão de ácido tereftálico da Aldrich ${ }^{\circledR}$ ( $98 \%$ de pureza).

\section{RESULTADOS E DISCUSSÃO}

\subsection{Reações de hidrólise de PET incolor em função da concentração de $\mathrm{NaOH}$}

O rendimento da hidrólise, bem como o grau de pureza do TPA recuperado, em função da concentração de $\mathrm{NaOH}$ do meio reacional encontra-se na Figura 4. A análise da Figura 4 mostra que o grau de pureza do TPA é relativamente alto para todas as concentrações de $\mathrm{NaOH}$ investigadas, exceto para a de $10,0 \mathrm{~mol} \mathrm{~L}^{-1}$, onde uma queda significativa pode ser observada.

Vale ressaltar que o rendimento da hidrólise não seguiu a mesma tendência, visto que esse foi crescente e linear no intervalo entre 1,0 e 7,5 mol L-1, ocorrendo uma queda significativa em $10,0 \mathrm{~mol} \mathrm{~L}^{-1}$. Em princípio, esse resultado parece contrariar o esperado, visto que, o aumento da concentração do íon hidróxido (um bom agente nucleófilo) no meio deve favorecer o processo de despolimerização do PET, através do ataque ao carbono carbonílico do éster, formando álcool e o sal do seu respectivo ácido, o tereftalato de dissódio ( $\mathrm{Na}_{2}$-TPA). De fato, isso foi verificado na faixa de concentração entre 1,0 e 7,5 mol L ${ }^{-1}$; a partir dessa concentração é possível que a reação de despolimerização seja controlada pelo transporte de massa, ou seja, como essa é uma reação de superfície (sistema heterogêneo), a partir de uma concentração crítica de $\mathrm{OH}^{-}$, os próprios produtos formados (monômeros, dímeros, trímeros e etc.) podem ser adsorvidos à superfície do PET, sugerindo atuarem como um filme orgânico bloqueador durante a reação de hidrólise, dificultando o acesso dos íons hidróxidos a novos carbonos carbonílicos do PET não reagido e, consequentemente, diminuindo a eficiência do reação de hidrólise [38]. Contrariamente, em concentrações menores que $10,0 \mathrm{~mol} \mathrm{~L}^{-1}$, o processo de transferência de massa não interfere na reação e a cinética da mesma é controlada pela etapa química.

Face a esses resultados, a concentração de $7,5 \mathrm{~mol} \mathrm{~L}^{-1}$ pode ser considerada ótima para a reciclagem química de PET, visto que o rendimento da reação, bem como o grau de pureza do TPA foram máximos. Na presença de 1,0 e 3,0 mol L ${ }^{-1}$ de $\mathrm{NaOH}$, apesar da alta pureza do TPA, o rendimento da reação foi baixo. 


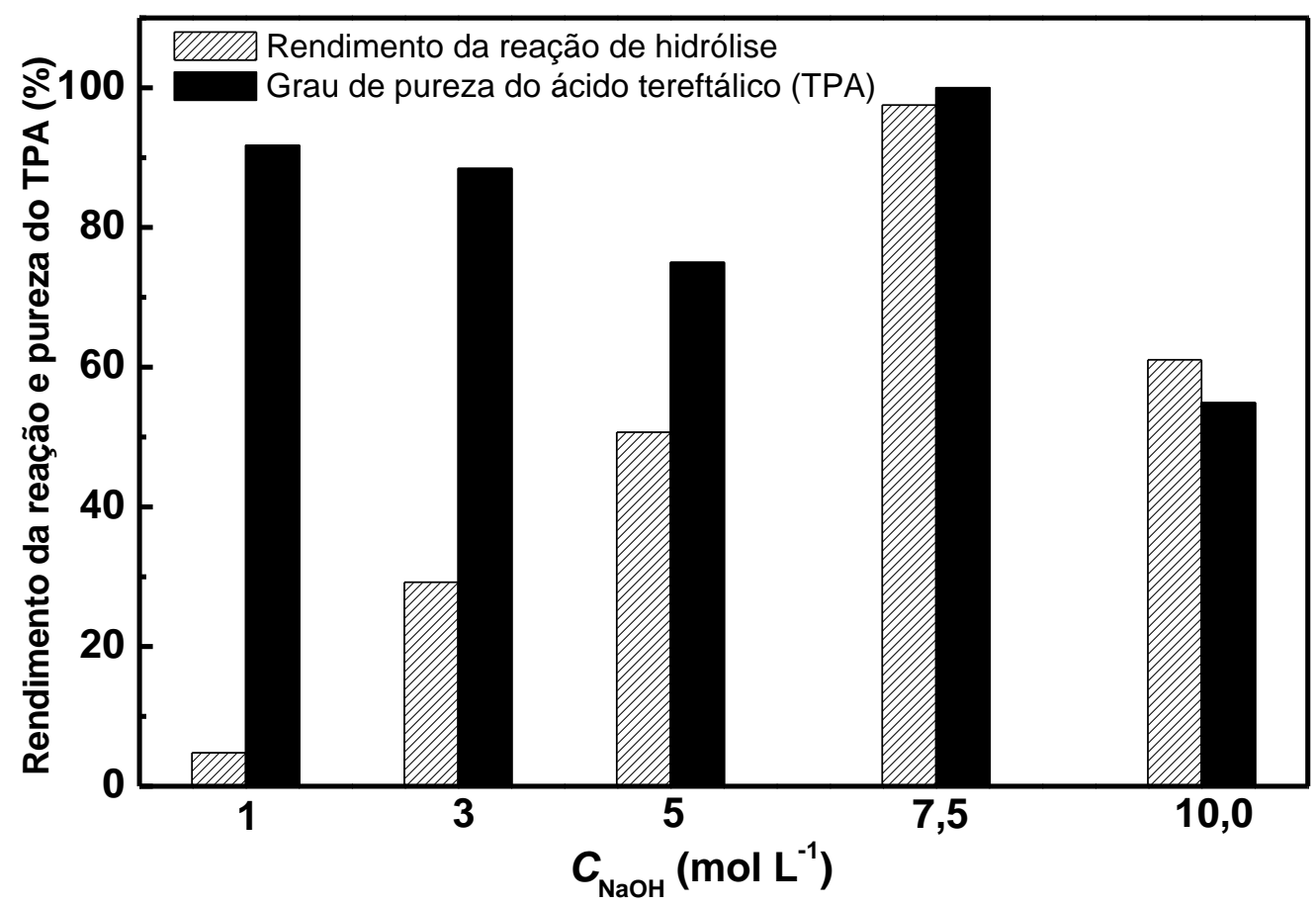

Figura 4: Grau de pureza do TPA e rendimento da hidrólise em função da concentração de $\mathrm{NaOH}$. O grau de pureza foi obtido por titulação potenciométrica ácido-base.

De acordo com MANCINI e ZANIN [20], o meio reacional que propiciou a maior reatividade do PET foi a solução de hidróxido de sódio, dentre as várias soluções investigadas, tais como ácido sulfúrico, ácido acético, água, acetato de sódio e hidróxido de sódio, sendo a concentração mantida constante em 7,5 mol L $\mathrm{L}^{-1}$. O tempo de reação foi de $5 \mathrm{~h}$ (material fino) ou de $7 \mathrm{~h}$ (material grosseiro). MANCINI e ZANIN [20] justificaram a escolha da concentração de $7,5 \mathrm{~mol} \mathrm{~L}^{-1}$ com base nos trabalhos de YOSHIOKA et al. [39] onde somente concentrações superiores a 7,0 mol L ${ }^{-1}$ de ácido sulfúrico foram capazes de despolimerizar todo o PET em $5 \mathrm{~h}$ de reação a $150{ }^{\circ} \mathrm{C}$ num ambiente pressurizado.

DI SOUZA et al. [30] também realizaram estudos de degradação de PET em solução de $\mathrm{NaOH}$,explorando diferentes variáveis como o tempo de reação, a área superficial do PET, a presença de tensoativos e a concentração de $\mathrm{NaOH}\left(7,5 \mathrm{~mol} \mathrm{~L}^{-1}\right.$ e excesso de solução alcalina). Foi observado que o rendimento da hidrólise de PET (partículas grosseiras: $30 \mathrm{~mm}^{2}$ ) aumentou significativamente, de $45 \%$, em solução 7,5 mol L ${ }^{-1}$ de $\mathrm{NaOH}$, para $99 \%$ em excesso de solução de $\mathrm{NaOH}$. Vale ressaltar que o tempo de reação foi de $6 \mathrm{~h}$.

No presente trabalho, o tempo de reação foi mantido em 8 h, ao invés de 6 h, e a área das partículas de PET foi de $25 \mathrm{~mm}^{2}$, ao invés de $30 \mathrm{~mm}^{2}$, o que pode explicar o rendimento da hidrólise ser significativamente maior $(95,1 \%)$ do que aquele obtido por DI SOUZA et al. [30] (45\%), nas mesmas condições experimentais de temperatura, pressão $\left(100{ }^{\circ} \mathrm{C}, 1 \mathrm{~atm}\right)$ e concentração de $\mathrm{NaOH}\left(7,5 \mathrm{~mol} \mathrm{~L}^{-1}\right)$. Outro fator que pode ter contribuído para essa diferença é a maneira de obtenção dos dados de rendimento da reação e grau de pureza do TPA. No presente caso, foram obtidos pela Eq. (1) e por titulação ácido-base, respectivamente. DI SOUZA et al. [30] usaram outra metodologia; eles calcularam o rendimento da reação a partir da massa recuperada de TPA e da fração de ácido tereftálico teoricamente presente no PET, obtida estequiometricamente. Não ficou claro como o grau de pureza foi obtido, mas ambos os valores situaram-se em aproximadamente $98 \%$ em média.

Apesar de evidências de que a concentração de $\mathrm{NaOH}$ influencia no rendimento da reação de hidrólise de PET [20,28,30], um estudo sistemático considerando essa variável não foi encontrado na literatura. $\mathrm{O}$ valor crescente do rendimento da reação com a concentração de $\mathrm{NaOH}$ pode ser explicado da seguinte maneira: [30,40] o íon hidróxido aumenta a velocidade das duas etapas lentas da reação: i) formação do intermediário tetraédrico porque o íon $\mathrm{OH}^{-}$é um nucleófilo melhor do que a água, assim o íon $\mathrm{OH}^{-}$ataca mais rapidamente o carbono carbonílico; ii) colapso do intermediário tetraédrico, facilitando a eliminação do grupo de saída $\left(\mathrm{RO}^{-}\right)$. Quando o grupo $\mathrm{RO}^{-}$é eliminado, os produtos finais são um íon carboxilato e um álcool. Essa reação é chamada reação promovida pelo íon hidróxido e não reação catalisada por base, porque 
o íon hidróxido aumenta a velocidade da primeira etapa da reação por ser um nucleófilo melhor do que a água e porque é consumido no término da reação. Assim, o íon hidróxido é, na realidade, um reagente, e não um catalisador.

ROSMANINHO et al. [3,29] estudaram a reação de hidrólise parcial de PET, em soluções de $\mathrm{NaOH}$ $\left(1 ; 5\right.$ e $\left.10 \mathrm{~mol} \mathrm{~L}^{-1}\right)$ e de $\mathrm{HNO}_{3}\left(7,5 ; 10\right.$ e $\left.15 \mathrm{~mol} \mathrm{~L}^{-1}\right)$, com vistas à aplicação do PET quimicamente modificado como adsorvente de contaminantes catiônicos em água. Nesses estudos [3,29], para concentrações de até $5 \mathrm{~mol} \mathrm{~L}^{-1}$ de $\mathrm{NaOH}$ o rendimento da hidrólise foi de $\sim 10 \%$ após $120 \mathrm{~min}$; para concentração de base de $10 \mathrm{~mol} \mathrm{~L}^{-1}$, mais de $90 \%$ do PET foi hidrolisado no mesmo intervalo de tempo. Esses resultados corroboram os nossos estudos no que tange o elevado rendimento da reação em maiores concentrações da base. No entanto, a concentração de 7,0 ou 7,5 mol L-1, que de acordo com os nossos resultados forneceu bons resultados, não foi investigada por ROSMANINHO et al. [3,29]. Ressalta-se que é vantajoso conduzir a reação na presença de $7,5 \mathrm{~mol} \mathrm{~L}^{-1}$, ao invés de $10 \mathrm{~mol} \mathrm{~L}^{-1}$, por questão econômica e também por minimizar impurezas de carbonato que podem estar presentes no estoque de $\mathrm{NaOH}$.

Com relação ao grau de pureza do TPA, nota-se que os valores são relativamente altos, e independem do rendimento da reação ou da concentração de $\mathrm{NaOH}$ (Figura 4), permitindo dizer que o processo de obtenção/purificação de TPA empregado nesse trabalho (Figura 3) pode ser considerado satisfatório. No entanto, considerando o retorno do TPA para as plantas de produção de garrafas PET, é importante garantir uma pureza superior a 99,5\% [20]. Pureza inferior a essa fornece baixa produtividade na esterificação direta com o etilenoglicol[20].

\subsection{Reações de hidrólise de PET em função da cor}

Visto que a reação de hidrólise em meio de 7,5 $\mathrm{mol} \mathrm{L}^{-1}$ de $\mathrm{NaOH}$ resultou em maior rendimento e grau de pureza de TPA (Figura 4), fixou-se essa concentração e realizou-se a reação de hidrólise de PET de diferentes cores (amarelo, azul, verde e vermelho). Vale ressaltar que não encontrou-se, na literatura, estudos de reciclagem química de PET colorido. As diferentes cores das embalagens de PET são obtidas adicionando corantes à estrutura polimérica, no intuito de dar-lhes uma melhor aparência e, principalmente, para protegerem o conteúdo armazenado em suas embalagens contra a incidência da radiação ultravioleta. Dentre os corantes que melhores se prestam a essa função são os orgânicos e pertencentes às classes das ftalocianinas e antraquinonas [41].

A Figura 5 mostra curvas de titulação potenciométrica representativas, a partir das quais os valores de \%pureza dos produtos das reações de despolimerização foram determinados. Como referencial, as curvas obtidas para o TPA comercial também são mostradas na Figura 5.

Observa-se, a partir da Figura 6, que tanto o rendimento da hidrólise, como o grau de pureza do TPA, sofreu diminuição quando a reação se processou com PET colorido, tendo como referência o PET incolor.Uma possível explicação para o resultado da diminuição do rendimento da hidrólise está relacionada à presença de corantes (ftalocianinas/antraquinonas) na composição química de PET colorido, que prejudicam os processos de despolimerização. O fato dos corantes apresentarem também carbonos eletrofílicos em suas estruturas moleculares é esperada uma diminuição da seletividade do ataque da hidroxila (nucleófilo) aos carbonos eletrofílicos do PET, o que acarreta, como consequência, uma diminuição do rendimento da reação de despolimerização do próprio PET. Essa diminuição do rendimento de reação também está relacionada com a diminuição do grau de pureza de TPA recuperado da reação de despolimerização. Uma vez que a quantidade de hidroxila disponível no meio reacional diminui em função de seu consumo pela reação química com os corantes presentes nas amostras, esse fato leva à diminuição da eficiência da reação de despolimerização do PET. Com a diminuição da reação de despolimerização para formação de TPA, esse resultado sugere ocorrer a formação de dímeros, trímeros e polímeros do material PET, sendo que essas espécies de polímeros contribuem para a diminuição do grau de pureza das amostras analisadas.Os valores de rendimento da hidrólise situaram-se entre 66,6\% (PET vermelho) e 85,5\% (PET amarelo) e os graus de pureza entre 61,7\% (PET amarelo) e 83,4\% (PET vermelho), contra valores de 97,5\% (rendimento) e $100 \%$ (grau de pureza), obtidos para PET incolor. 

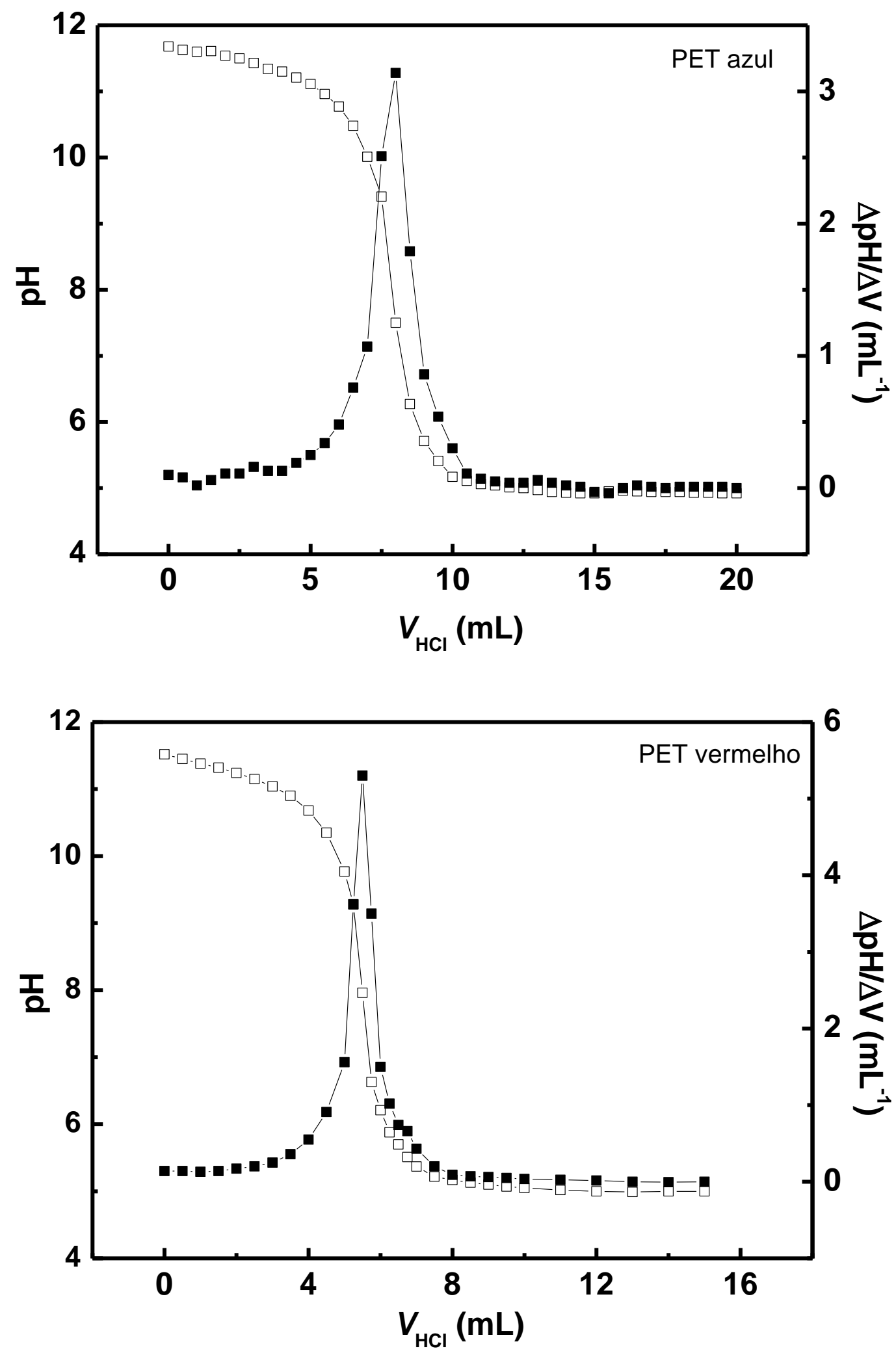


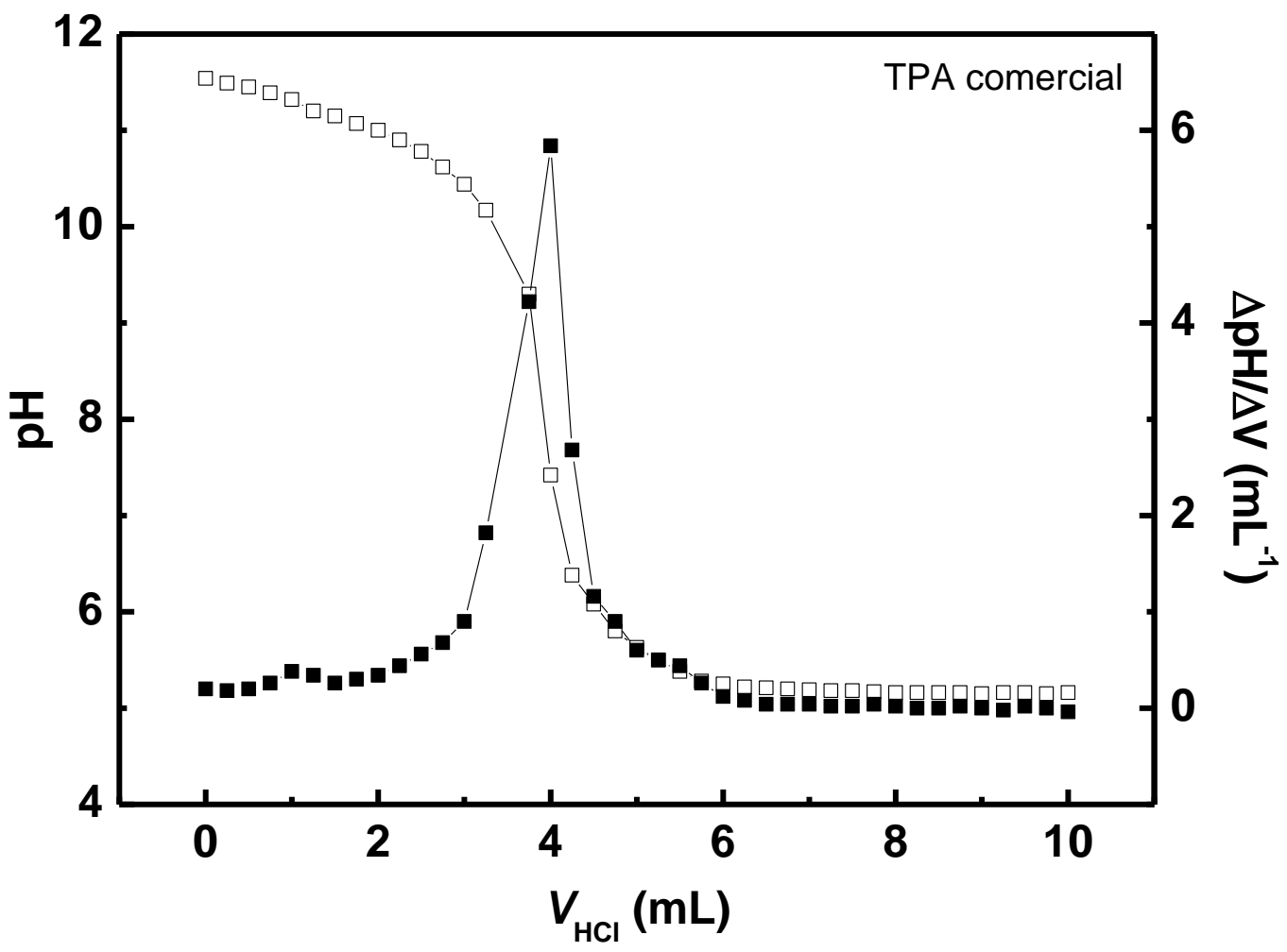

Figura 5: Curvas de titulação potenciométrica dos produtos das reações de despolimerização de PET azul, vermelho e do TPA comercial. (__ _ _ $)$ pH vs. volume; (___ c curva da $1^{\mathrm{a}}$ derivada.

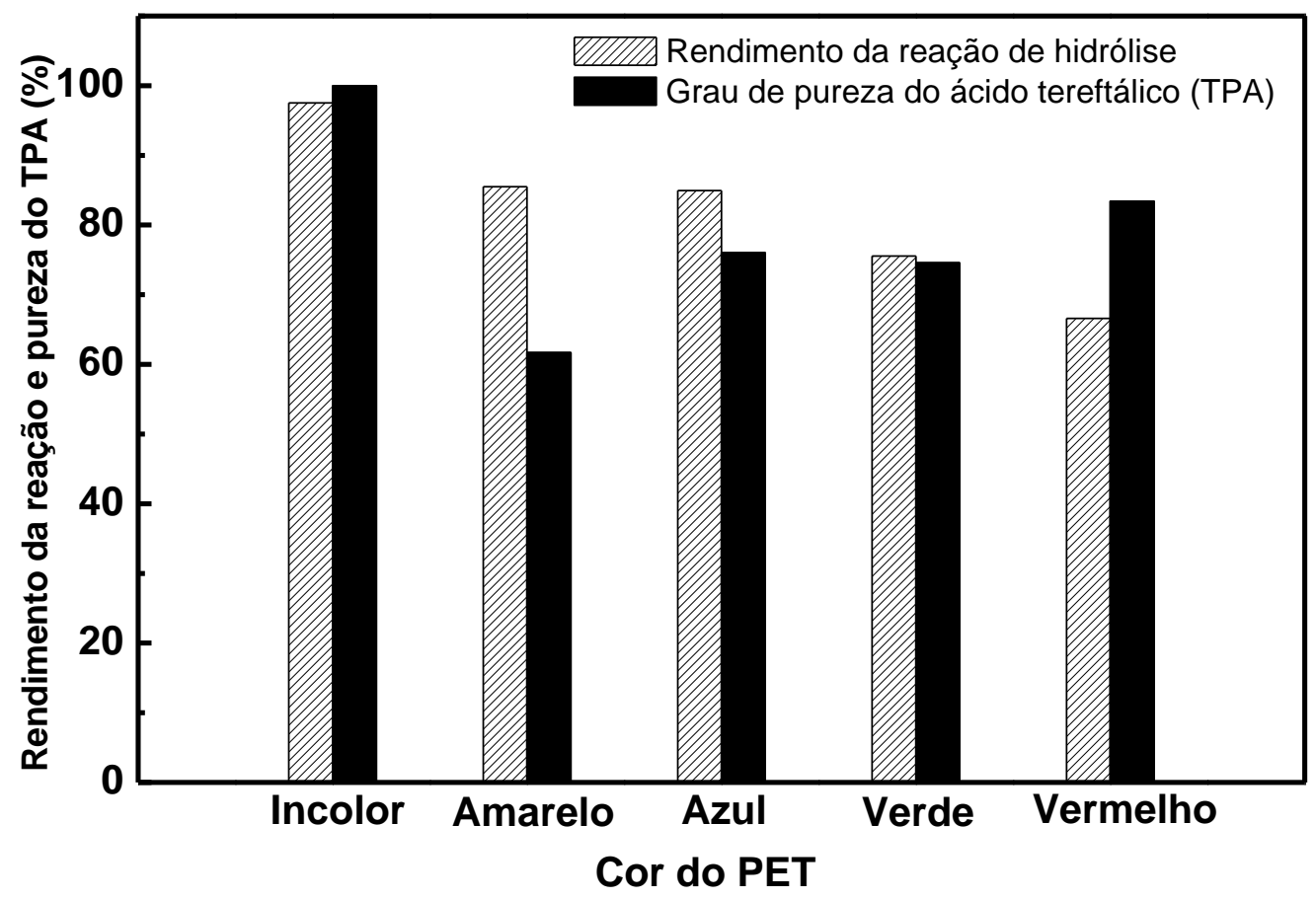

Figura 6: Grau de pureza do TPA e rendimento da hidrólise em função da cor do PET.

\subsection{Reações de hidrólise de PET incolor em função do tempo}

Quanto ao estudo do tempo reacional, quanto maior o tempo de reação, maior o rendimento da reação (vide 
Figura 7), o que é compreensível considerando que a reação acontece na interface sólido (PET)-fase aquosa. Um modelo simples considerando a reação na superfície do PET é o shrinking core, um processo no qual a partícula sólida do PET é hidrolisada em sua superfície levando a um decréscimo constante no tamanho da partícula [29]. Os valores de porcentagem de pureza dos produtos obtidos a partir das reações realizadas em tempos de 1; 2; 4 e $6 \mathrm{~h}$ são significativamente inferiores àquele obtido em $8 \mathrm{~h}$, que é de $100 \%$, o que confirma que esse tempo é o mais indicado, aliado à concentração da base de $7,5 \mathrm{~mol} \mathrm{~L}^{-1}$.

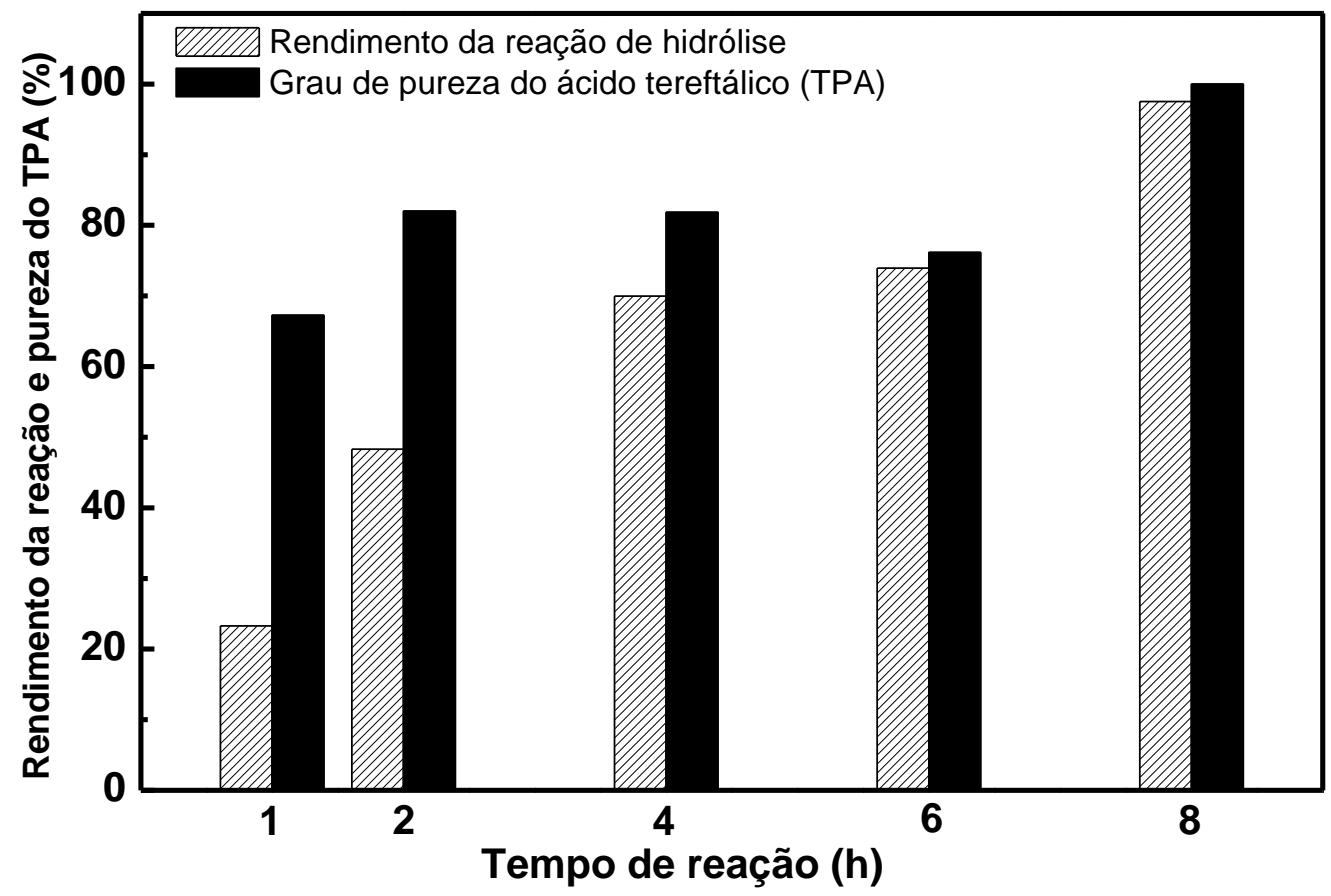

Figura 7: Grau de pureza do TPA e rendimento da hidrólise em função do tempo de reação.

\subsection{Caracterização dos produtos da reação de hidrólise do PET por espectroscopia no infravermelho (FTIR), difração de raios $\mathrm{X}$ (DRX) e análise termogravimétrica (TGA/DTG)}

A Figura 8 apresenta espectros representativos das análises realizadas por FTIR dos produtos obtidos (supondo que se trata de TPA) a partir das reações de hidrólise em meio alcalino, para PET incolor e colorido (azul e verde). As análises foram realizadas para os produtos obtidos na presença de 7,5 mol L ${ }^{-1} \mathrm{de} \mathrm{NaOH}$, visto que foi a condição de reação que conduziu aos melhores resultados, tanto de rendimento, como de grau de pureza. Após a análise dos resultados, todos os espectros obtidos praticamente se sobrepõem àquele obtido para o TPA comercial, da Aldrich ${ }^{\circledR}$ (compare Figuras $8 \mathrm{a}$ e b).

Esses resultados, quando confrontados com aqueles apresentados na literatura [20], corroboram que o produto das reações estudadas realmente trata-se do TPA. De forma geral, os espectros são constituídos pela banda larga entre 3400 e $2200 \mathrm{~cm}^{-1}$, correspondente ao grupo -OH ligado à carbonila, bem como do pico da carbonila, localizado em $1680 \mathrm{~cm}^{-1}$ [20].

Segundo DI SOUZA et al. [30] os picos na região entre 3010 e $3100 \mathrm{~cm}^{-1}$ correspondem à ligação CH (aromático) e resultam de resíduos de síntese. De acordo com a literatura [42], o TPA é produzido a partir da oxidação do $p$-xileno com ácido acético; industrialmente, a sua purificação é realizada a partir de sublimação fracionada [43] ou de outros métodos de purificação desenvolvidos posteriormente [44,45]. 


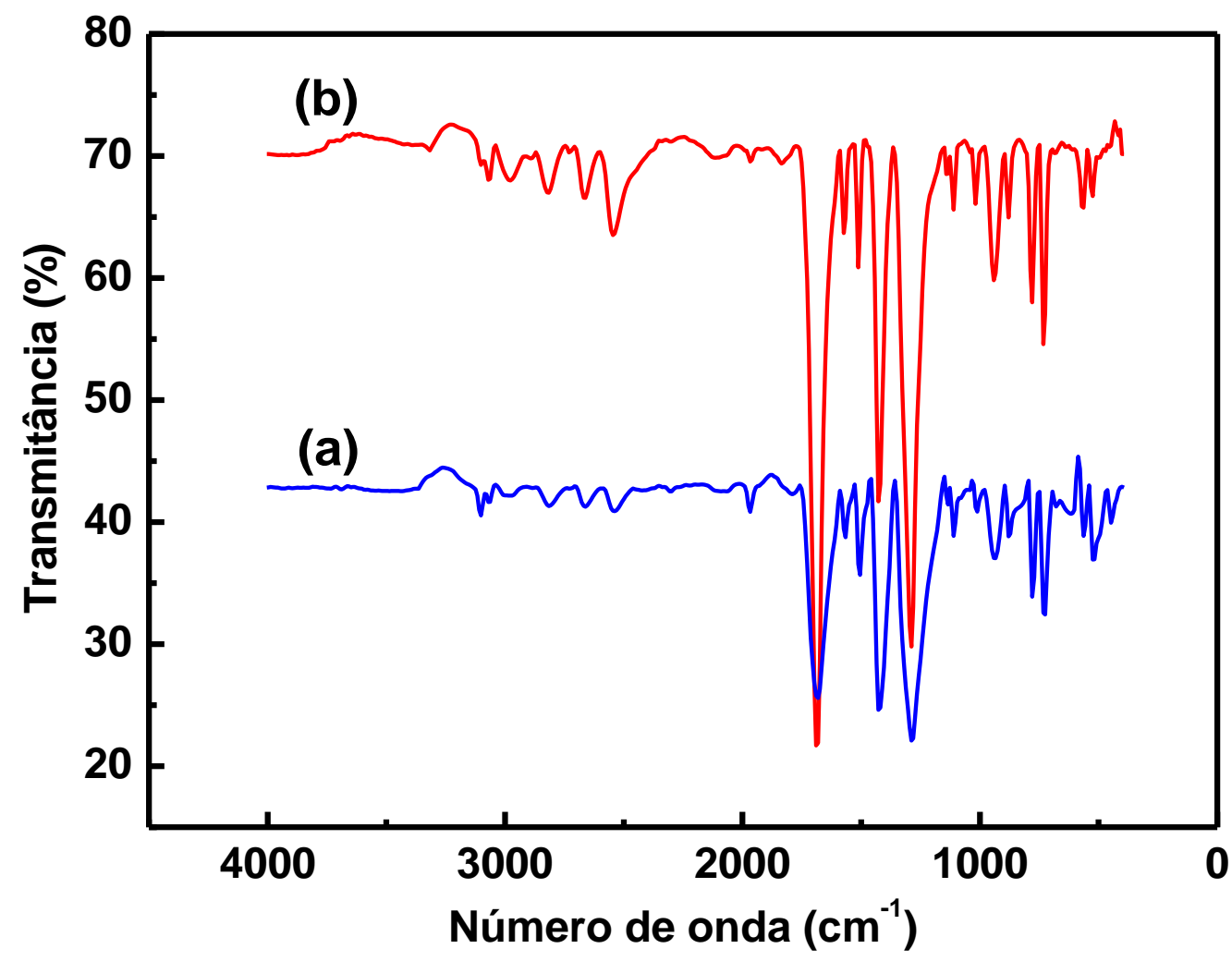

Figura 8: Espectros no infravermelho do TPA comercial, padrão (a) e do produto recuperado a partir da reação de hidrólise de PET incolor, $\mathrm{C}_{\mathrm{NaOH}}=7,5 \mathrm{~mol} \mathrm{~L}^{-1}(\mathrm{~b})$.

A Figura 9 apresenta os difratogramas do TPA recuperado nesse trabalho, bem como aquele do TPA comercial; as medidas foram realizadas para as mesmas amostras para as quais foram obtidos os espectros no infravermelho. A partir da análise dos picos de difração, bem definidos, pode-se dizer que o produto obtido trata-se de um composto cristalino, o ácido tereftálico, visto que os picos coincidem com aqueles do padrão comercial, confirmando mais uma vez que a reação de hidrólise foi conduzida satisfatoriamente nessas condições $\left(7,5 \mathrm{~mol} \mathrm{~L}^{-1} \mathrm{NaOH}, 1\right.$ atm e $\left.100{ }^{\circ} \mathrm{C}\right)$.

Vale ressaltar que a literatura consultada não utilizou essa técnica para caracterizar o produto obtido a partir da despolimerização de PET, porém isso é perfeitamente possível. A única informação encontrada [2] é que o polímero PET apresenta elevado percentual de cristalinidade, o que corrobora o fato do TPA também ser um pó branco, de natureza cristalina, conforme mostrado neste trabalho. 


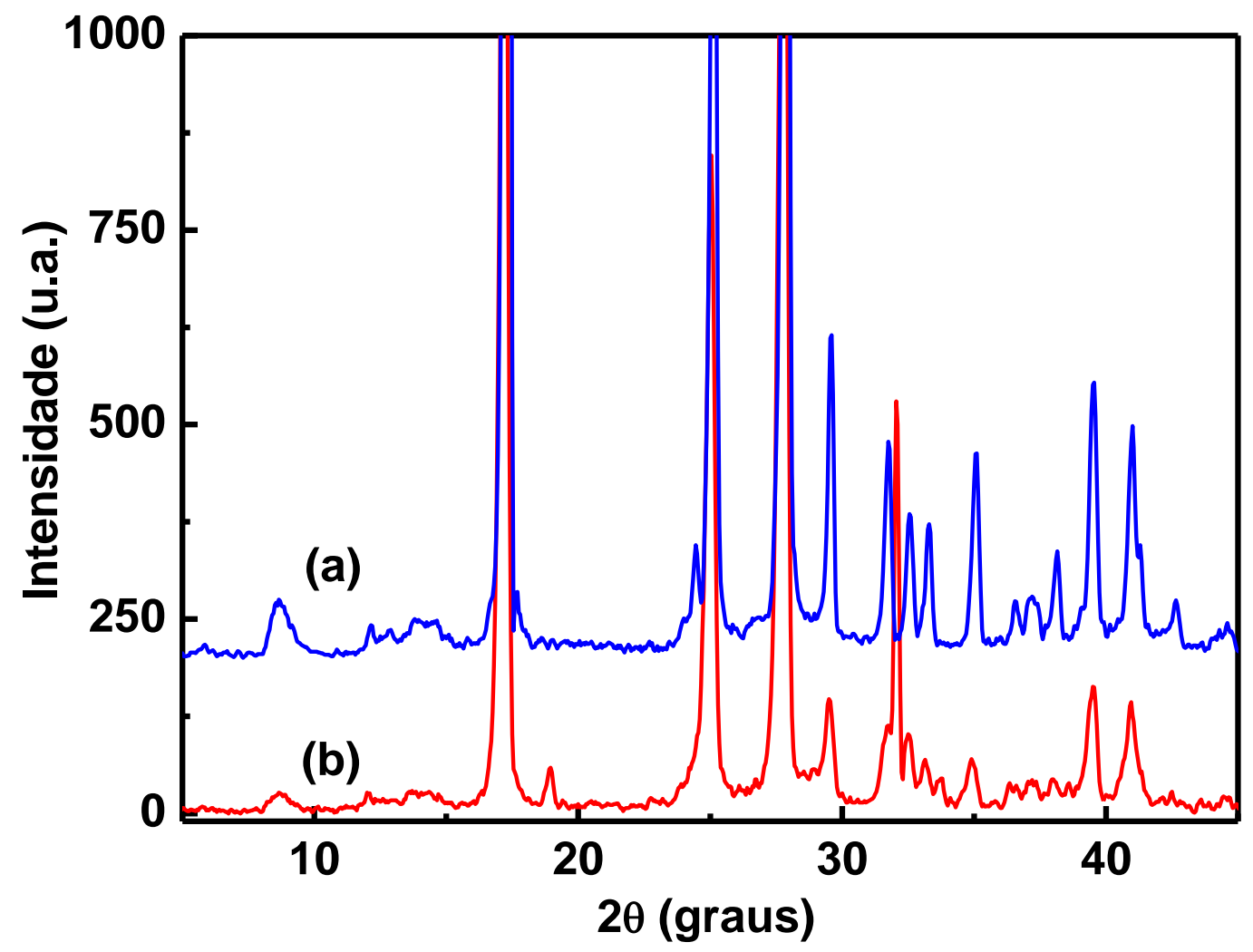

Figura 9: Difratogramas do: (a) TPA comercial padrão e (b) produto recuperado a partir da reação de hidrólise de PET incolor, $\mathrm{C}_{\mathrm{NaOH}}=7,5 \mathrm{~mol} \mathrm{~L}^{-1}$.

No intuito de se analisar a pureza do TPA obtido a partir de reação de hidrólise em meio alcalino bem como a sua propriedade de estabilidade térmica, comparada com uma amostra de TPA comercial, foram realizadas análises térmicas por meio da análise termogravimétrica (TG) e termogravimetria derivada (DTG). A Figura 10 mostra que as curvas TGA/DTG para o TPA recuperado e o comercial são praticamente idênticas, com única perda de massa no intervalo de perda 250 e $360{ }^{\circ} \mathrm{C}$, com os pontos máximos das derivadas em $345,16{ }^{\circ} \mathrm{C}$ (TPA recuperado) e $350,75{ }^{\circ} \mathrm{C}$ (TPA comercial). Os resultados confirmaram que o produto recuperado é o TPA, apresentando mecanismo de decomposição térmica idêntico ao TPA comercial [30,32]. Uma comparação do resíduo de $4,18 \%$ para o TPA recuperado com $0,15 \%$ para o TPA comercial evidencia impurezas inorgânicas no TPA recuperado, que não foram decompostas até a temperatura de 900 ${ }^{\circ} \mathrm{C}[30]$. 


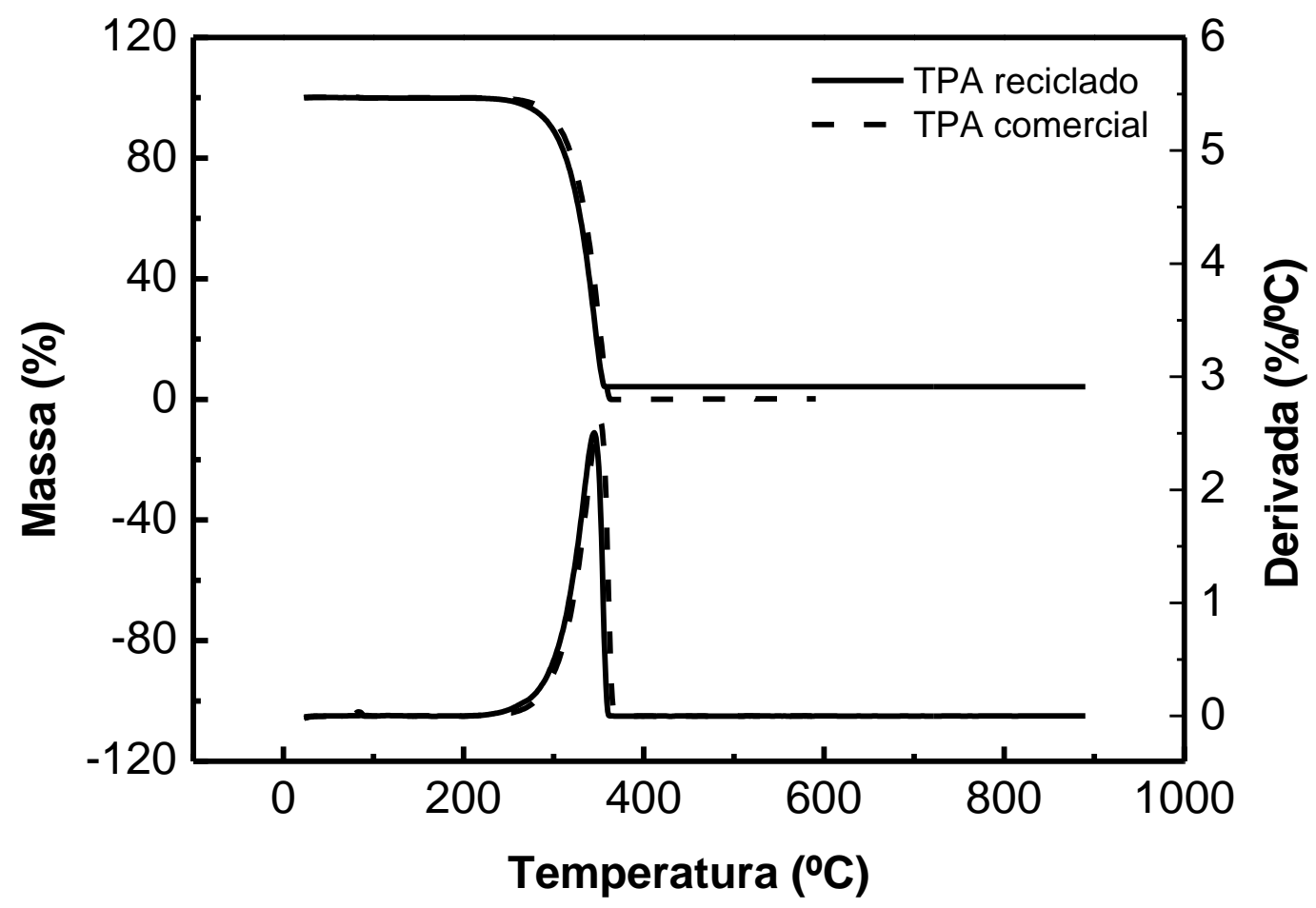

Figura 10: Curvas TGA/DTG para TPA reciclado e comercial com razão de aquecimento $10^{\circ} \mathrm{C} \min ^{-1}$ e vazão de ar sintético $100 \mathrm{mLmin}^{-1}$.

\section{CONCLUSÕES}

A reciclagem de plásticos continua sendo uma tarefa desafiadora no gerenciamento de resíduos urbanos. A qualidade do plástico reciclado é uma grande preocupação, destacando aspectos como contaminação cruzada de polímeros, aditivos, impurezas não-poliméricas e degradação. As propriedades físicas e químicas do produto recuperado pelo processo hidrolítico confirmaram que a qualidade do TPA reciclado é semelhante àquela do monômero comercial produzido na indústria petroquímica pela oxidação do $p$-xileno. Os pigmentos coloridos adicionados ao PET afetaram o rendimento da reação e o teor de pureza em comparação com as embalagens de PET incolor. O processo desenvolvido no presente trabalho é interessante do ponto de vista tecnológico, uma vez que permite que a reciclagem química do PET seja realizada à pressão atmosférica, e não em alta pressão, conforme relatado em outros trabalhos.

Dessa forma, destacam-se dois pontos impactantes do presente estudo, tanto no meio acadêmico como no industrial: a) o alto rendimento e pureza do TPA recuperado a partir do PET incolor e b) a adição de aditivos afeta a qualidade do TPA recuperado a partir do PET colorido.

O elevado teor de pureza do TPA recuperado da despolimerização hidrolítica do PET incolor torna-o promissor para a produção de TPA com boas qualidades para retornar para a produção de PET destinado ao acondicionamento em contato direto com alimentos. Há uma grande possibilidade de dispensar as análises químicas frequentes e os processos dispendiosos de descontaminação utilizados no processo de reciclagem mecânica. A qualidade do TPA também contrapõe-se aos investimentos elevados com reagentes químicos e, consequentemente, maior consumo de energia envolvendo a cadeia de produção do TPA reciclado. Ainda, o material de descarte das embalagens PET pós-uso passa a apresentar um maior o valor agregado, já que mostrou-se a possibilidade de o mesmo retornar para as plantas de produção de PET. Além da questão ambiental, o reaproveitamento de matéria prima traz conscientização no meio acadêmico e desenvolvimento de novas tecnologias que poderão ser repassadas para o setor produtivo. Conhecendo os resultados promissores, é possível que a indústria se interesse em implementar a tecnologia da reciclagem química de PET, sobretudo devido à importância desse assunto no panorama mundial atual no que diz respeito à preservação do meio ambiente e de sustentabilidade do Planeta. 


\section{AGRADECIMENTOS}

À FAPEMIG, pelo apoio financeiro (Processo CEX-APQ-00585-11) e pela bolsa de IC de C.M.A.S.. A presente publicação faz parte de um projeto de pesquisa em colaboração com os membros da Rede Mineira de Química (RQ-MG), apoiado pela FAPEMIG (Processos: REDE-113/10; CEX-RED-00010-14).

\section{BIBLIOGRAFIA}

[1] PET, FICHAS TÉCNICAS, Compromisso Empresarial para Reciclagem (CEMPRE), http://cempre.org.br/artigo-publicacao/ficha-tecnica/id/8/pet. Acessado em agosto de 2017.

[2] BANNACH, G., PERPÉTUO, G.L., CAVALHEIRO, E.T.G., et al., "Efeitos da história térmica nas propriedades do polímero PET: um experimento para ensino de análise térmica", Química Nova, v. 34, n. 10, pp. 1825-1829, Jul.2011.

[3] ROSMANINHO, M.G., JARDIM, E., FERREIRA, G.L., et al., "Hidrólise parcial da superfície do polyethyleneterephthalate (PET): transformando um rejeito em um material de troca catiônica para aplicação ambiental", Química Nova, v.32. n. 6, pp. 1673-1676, Jul.2009.

[4] Censo da reciclagem do PET no Brasil, 10ª Edição, Associação Brasileira da Indústria do PET (ABIPET), http://www.abipet.org.br/index.html?method=mostrarDownloads\&categoria.id=3. Acessado em agosto de 2017.

[5] STATISTICAL DATA ANDRESEARCH, PLASTIC FACTS \& STATISTICS, Container RecyclingInstitute (CRI), http://www.container-recycling.org/index.php/factsstatistics/plastic. Acessado em agosto de 2017.

[6] MAGRINI, A., MELO, C.K., CASTOR JR., C.A., et al., Impactos ambientais causados pelos plásticos: uma discussão abrangente sobre os mitos e os dados científicos, Rio de Janeiro, E-papers Serviços Editoriais Ltda., 2012.

[7] ATITUDES SUSTENTÁVEIS E ECONOMIA, Sustentabilidade: resíduo zero e clima, AnheuserBuschInbev (Ambev), https://www.ambev.com.br/sustentabilidade/residuo-zero-e-clima/. Acessado em agosto de 2017.

[8] USO DE PET RECICLADO em embalagens e outros materiais destinados ao contato com alimentos, Informe Técnico n. 71, de 11 de fevereiro de 2016, Agência Nacional de Vigilância Sanitária (ANVISA), http://portal.anvisa.gov.br/documents/33916/388729/Informe+T\%C3\%A9cnico+n\%C2\%BA+71\%2C+de+11 +de+fevereiro+de+2016/e03dac30-111d-4793-a57e-a454a3862f74. Acessado em agosto de 2017.

[9] RECYCLED PLASTICS IN FOODPACKAGING, U.S. Departmentof Health andHuman Services, FoodandDrugAdministration (FDA),

https://www.fda.gov/Food/IngredientsPackagingLabeling/PackagingFCS/RecycledPlastics/default.htm. Acessado em agosto de 2017.

[10] SILANO, V., BOLOGNESI, C., CASTLE, L., et al., "Safetyassessmentoftheprocess 'EREMA recycling(MPR, basicandadvancedtechnologies)', usedtorecycle post-consumer PET intofoodcontactmaterials", EuropeanFoodSafetyAuthority, EFSA Journal,v. 15, n. 6, pp. 1-16, Jun. 2017.

[11] TECNOLOGIA DE RECICLAGEM, Associação Brasileira de Embalagem (ABRE),

http://www.abre.org.br/setor/apresentacao-do-setor/reciclagem/tecnologia-de-reciclagem/. Acessado em agosto de 2017.

[12] FABRICAÇÃO DAS GARRAFAS E FRASCOS: o sopro das pré-formas, Garrafas - Fabricação, Associação Brasileira da Indústria do PET (ABIPET),

http://www.abipet.org.br/index.html?method=mostrarInstitucional\&id=71. Acessado em agosto de 2017.

[13] KUMAR, S., GURIA, C.J., "Alkalinehydrolysisofwastepoly(ethyleneterephthalate): a modifiedshrinking core model", Journal of Macromolecular Science, Part A: Pure and Applied Chemistry, v. 42, n.3, pp. 237$251,2005$.

[14] GOJE, A.S., THAKUR, S.A., DIWARE, V.R., et al., "Aminolysis of poly(ethylene terephthalate) waste for recovery of value added comonomeric product", Polymer-Plastics Technology And Engineering, v. 43, n. 2, pp.407-426, 2004.

[15] DANNOUX, M., CASSAGNAU, P., MICHEL, A., "Synthesis of oligoester $\alpha, \omega$-diols by alcoholysis of PET through the reactive extrusion process", The Canadian Journal of Chemical Engineering, v.80, n. 6, pp. 1075-1082, Dez. 2002.

[16] COLOMINES, G., RIVAS, F., LACOSTE, M.L., et al., "Study of polyurethane formulations containing 
diols obtained via glycolysis of poly (ethylene terephthalate)(PET) by oligoesters diols through a reactive extrusion process", Macromolecular Materials and Engineering, v. 290, n. 7, pp. 710-720, Jul. 2005.

[17] BALDISSERA, A.E., VALERIO, C.E.S., BASSO, N.R.D., et al., "Synthesisand NMR characterizationofaliphatic-aromaticcopolyestersbyreactionofpoly(ethyleneterephthalate) postconsumerandpoly(ethyleneadipate)", Química Nova, v.28, n. 2, pp. 188-191, Abr.2005.

[18] NIKLES, D.E., FARAHAT, M.S., "New motivation for the depolymerization products derived from poly (ethylene terephthalate)(PET) waste: a review", Macromolecular Materials and Engineering, v. 290, n. 1, pp. 13-30, Jan. 2005.

[19] $6^{\circ}$ SENSO DA RECICLAGEM QUÍMICA DO PET NO BRASIL, Associação Brasileira da Indústria do PET (ABIPET), http://www.abipet.org.br/index.html?method=mostrarDownloads\&categoria.id=3. Acessado em agosto de 2017.

[20] MANCINI, S.D., ZANIN, M., "Influência de meiosreacionaisnahidrólise de PET pós-consumo", Polímeros: Ciência e Tecnologia, v. 12, n. 1, pp. 34-40, Feb. 2002.

[21] PASZUN, D., SPYCHAJ, T., "ChemicalRecyclingofPoly(ethyleneterephthalate)", Industrial \&Engineering Chemistry Research, v. 36, n. 4, pp. 1373-1383, Abr. 1997.

[22] BUXBAUM, L.H., "The degradation of poly (ethylene terephthalate)",AngewandteChemie International Edition, v. 7, n. 3, pp. 182-190, Mar. 1968.

[23] ALLEN, N.S., EDGE, M., MOHAMMADIAN, M., JONES, K., "Physicochemical aspects of the environmental degradation of poly(ethylene terephthalate)", Polymer Degradation and Stability, v. 43, n. 2, pp. 229-237, Jul. 1994.

[24] REICH, L., STIVALA, S.S., Elements of Polymer Degradation, New York, Mcgraw Hill, 1971.

[25] DONAHUE, C.J., EXLINE, J.A., WARNER, C., "Chemicalrecyclingof pop bottles: The synthesisofdibenzylterephthalatefromtheplasticpolyethyleneterephthalate", Journal of Chemical Education, v. 80, n. 1, pp. 79, Jan. 2003.

[26] SHUKLA, S.R., HARAD, A.M., "Aminolysis of polyethylene terephthalate waste", Polymer Degradation and Stability, v.91, n. 8, pp. 1850-1854, Ago. 2006.

[27] MANSOUR, S.H., IKLADIOUS, N.E., "Depolymerization of poly(ethylene terephthalate) wastes using 1, 4-butanediol and triethyleneglycol", Polymer Testing, v. 21, n. 5, pp. 497-505, Set. 2002.

[28] YOSHIOKA, T., MOTOKI, T., OKUWAKI, A., "Kinetics of hydrolysis of poly(ethylene terephthalate) powder in sulfuric acid by a modified shrinking-core model", Industrial \&Engineering Chemistry Research, v. 40, n. 1, pp. 75-79, Jan. 2001.

[29] ROSMANINHO, M.G., JARDIM, E., FERREIRA, G.L., et al., "Hidrólise parcial da superfície do polyethyleneterephthalate (PET): transformando um rejeito em um material de troca catiônica para aplicação ambiental", Química Nova, v. 32, n. 6, pp. S1-S6, Jul. 2009.

[30] DI SOUZA,L., TORRES, M.C.M., RUVOLO FILHO, A.C., "Despolimerização do poli(tereftalato de etileno) - PET: efeitos de tensoativos e excesso de soluçãoalcalina", Polímeros: Ciência e Tecnologia, v. 18, n. 4, pp. 334-341, Jun. 2008.

[31] CAMPANELLI, J.R., COOPER, D.G., KAMAL, M.R., "Catalyzed hydrolysis of polyethylene terephthalate melts",Journal of Applied Polymer Science, v. 53, n. 8, pp. 985-991, Ago. 1994.

[32] VANINI, G., CASTRO, E.V.R., SILVA FILHO, E.A., et al., "Despolimerização química de PET grau garrafa pós-consumo na presença de um catalisador catiônico, o brometo de hexadeciltrimetrilamônio (CTAB)", Polímeros, v. 23, n. 3, pp. 425-431, Mai. 2013.

[33] FONSECA, T.G., ALMEIDA, Y.M.B., VINHAS, G.M., "Reciclagem química do PET pós-consumo: caracterização estrutural do ácido tereftálico e efeito da hidrólise alcalina em baixa temperatura", Polímeros, v. 24, n. 5, Set. 2014.

[34] CAREY, J., "News Feature: Onthebrinkof a recyclingrevolution?",

ProceedingoftheNationalAcademyofSciencesofthe United StatesofAmerica, v. 114, n. 4, pp. 612-616, Jan.

2017.

[35] FUJUSHIMA, K., LECUYER, J.M., WEI, D.S., et al.,

"Advancedchemicalrecyclingofpoly(ethyleneterephthalate) throughorganocatalyticaminolysis",

PolymerChemistry, v. 4, n. 5, pp. 1610-1616,Mar. 2013.

[36] CHALLENGES IN PLASTICS RECYCLING, TechnicalUniversityofDenmark, 
http://orbit.dtu.dk/files/118106943/Plastics_published.pdf. Acessado em agosto de 2017.

[37] RAHIMI, A., GARCÍA, J.M., “Chemicalrecyclingofwasteplastics for new materialsproduction”, Nature Reviews Chemistry, v. 1, n. 6, Jun. 2017.

[38] CURTI, P.S., RUVOLO, A.F, "Kinetics study of the heterogeneous depolymerization of waste PET in alkaline medium: stirring rate effect",Polímeros: Ciência e Tecnologia, v. 16, n. 4, pp. 276-285, Jul. 2006.

[39] YOSHIOKA, T., SATO, T., OKUWAKI, A., "Hydrolysis of waste PET by sulfuric acid at $150^{\circ} \mathrm{C}$ for a chemical recycling”,Journal of Applied Polymer Science, v. 52, n. 9, pp. 1353-1355, Mai. 1994.

[40] BRUICE, P.Y., Química orgânica: volume 2, 4ed., tradução D. O. Futuro (Coord.) et al., São Paulo, Prentice Hall, 2010.

[41] STEFANELLI, T.K.T.D.,Remoção de corante de poli(tereftalato de etileno) (PET) através de recristalização e sua posterior despolimerização em meio ácido, Dissertação de mestrado em Engenharia Química, UNICAMP, Campinas, SP, Brasil, 2013.

[42] ROMÃO, W., SPINACÉ, M.A.S., DE PAOLI, M.A., "Poli(tereftalato de etileno), PET: umarevisãosobreosprocessos de síntese, mecanismos de degradação e suareciclagem", Polímeros: Ciência e Tecnologia, v. 19, n. 2, pp. 121-132, Jan. 2009.

[43] BRYANT, H.S., DUVAL, C.A., MCMAKIN, L.E., et al., "Mobils process for TPA", Chemical Engineering Progress, v. 7, n. 9, pp. 69-75, 1971.

[44] PARTENHEIMER, W., GRAZIANO, D. J., US Pat. 5081290, 1992.

[45] PERNICONE, N., CERBONI, M., PRELAZZI, G., et al., "An investigation on Pd/C industrial catalysts for the purification of terephthalic acid”, Catalysis Today, v. 44, n. 1, pp. 129-135, Set. 1998. 